Marquette University

e-Publications@Marquette

\title{
From Micro to Macro-Contaminants: The Impact of Low-Energy Titanium Dioxide Photocatalysis Followed by Filtration on The Mitigation of Drinking Water Organics
}

\author{
Brooke K. Mayer \\ Marquette University, Brooke.Mayer@marquette.edu \\ Carlan Johnson \\ Marquette University \\ Yu Yang \\ Marquette University \\ Nicole Wellenstein \\ Marquette University \\ Emily K. Maher \\ Marquette University
}

See next page for additional authors

Follow this and additional works at: https://epublications.marquette.edu/civengin_fac

Part of the Civil Engineering Commons

\section{Recommended Citation}

Mayer, Brooke K.; Johnson, Carlan; Yang, Yu; Wellenstein, Nicole; Maher, Emily K.; and McNamara, Patrick J., "From Micro to Macro-Contaminants: The Impact of Low-Energy Titanium Dioxide Photocatalysis Followed by Filtration on The Mitigation of Drinking Water Organics" (2019). Civil and Environmental Engineering Faculty Research and Publications. 216.

https://epublications.marquette.edu/civengin_fac/216 
Authors

Brooke K. Mayer, Carlan Johnson, Yu Yang, Nicole Wellenstein, Emily K. Maher, and Patrick J. McNamara

This article is available at e-Publications@Marquette: https://epublications.marquette.edu/civengin_fac/216 
Marquette University

e-Publications@Marquette

\section{Civil, Construction and Environmental Engineering Faculty Research and Publications/College of Engineering}

This paper is NOT THE PUBLISHED VERSION; but the author's final, peer-reviewed manuscript. The published version may be accessed by following the link in th citation below.

Chemosphere, Vol. 217 (February 2019): 111-121. DOI. This article is C Elsevier and permission has been granted for this version to appear in e-Publications@Marquette. Elsevier does not grant permission for this article to be further copied/distributed or hosted elsewhere without the express permission from Elsevier.

\section{From Micro to Macro-Contaminants: The} Impact of Low-Energy Titanium Dioxide Photocatalysis Followed by Filtration on The Mitigation of Drinking Water Organics

Brooke K. Mayer

Department of Civil, Construction and Environmental Engineering, Marquette University, Milwaukee, WI

Carlan Johnson

Department of Civil, Construction and Environmental Engineering, Marquette University, Milwaukee, WI

Yu Yang

Department of Civil, Construction and Environmental Engineering, Marquette University, Milwaukee, WI

Nicole Wellenstein

Department of Civil, Construction and Environmental Engineering, Marquette University, Milwaukee, WI 


\section{Emily Maher}

Department of Civil, Construction and Environmental Engineering, Marquette University, Milwaukee, WI

\section{Patrick J. McNamara}

Department of Civil, Construction and Environmental Engineering, Marquette University, Milwaukee, WI

\section{Abstract}

This study evaluated strategies targeting macro- and micro-organic contaminant mitigation using lowenergy titanium dioxide photocatalysis. Energy inputs of 1, 2, and $5 \mathrm{kWh} \mathrm{m}^{-3}$ resulted in incomplete oxidation of macro-organic natural organic matter, signified by greater reductions of $U_{254}$ and specific ultraviolet UV absorbance (SUVA) in comparison to dissolved organic carbon (DOC). The rate of $U_{254}$ removal was 3 orders of magnitude greater than the rate of DOC degradation. Incomplete oxidation improved operation of downstream filtration processes. Photocatalysis at $2 \mathrm{kWh} \mathrm{m}^{-3}$ increased the bed life of downstream granular activated carbon (GAC) filtration by $340 \%$ relative to direct filtration pretreatment. Likewise, photocatalysis operated ahead of microfiltration decreased fouling, resulting in longer filter run times. Using $2 \mathrm{kWh} \mathrm{m}^{-3}$ photocatalysis increased filter run time by 36 times in comparison to direct filtration. Furthermore, levels of DOC and UV 254 in the membrane permeate improved (with no change in removal across the membrane) using low-energy photocatalysis pretreatments. While high-energy UV inputs provided high levels of removal of the estrogenic micro-organics estrone (E1), 17 $\beta$-estradiol (E2), estriol (E3), and 17 $\alpha$-ethynlestradiol (EE2), low-energy photocatalysis did not enhance removal of estrogens beyond levels achieved by photolysis alone. In the cases of $\mathrm{E} 1$ and E3, the addition of $\mathrm{TiO}_{2}$ as a photocatalyst reduced degradation rates of estrogens compared to UV photolysis. Overall, process electrical energy per order magnitude reductions (EEOs) greatly improved using photocatalysis, versus photolysis, for the macro-organics DOC, $\mathrm{UV}_{254}$, and SUVA; however, energy required for removal of estrogens was similar between photolysis and photocatalysis.

Graphical abstract

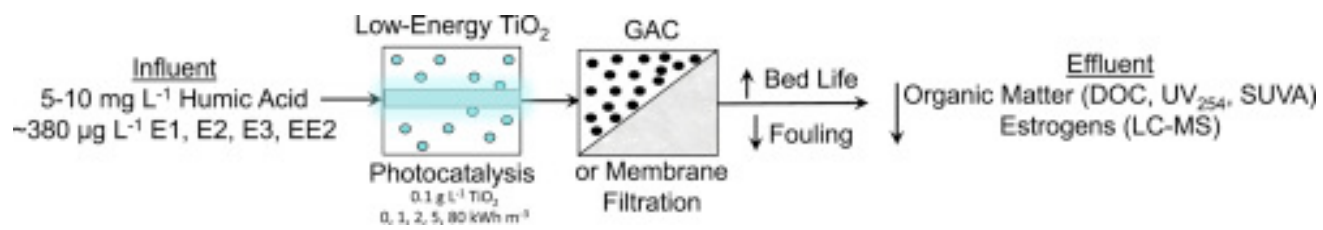

\section{Keywords}

UV photolysis, Natural organic matter (NOM), Dissolved organic carbon (DOC), Estrogens, Advanced oxidation process (AOP), Granular activated carbon (GAC)

\section{Introduction}

Advanced oxidation processes (AOPs) generate nonspecific reactive radical species, primarily hydroxyl radicals $(\mathrm{HO} \bullet)$, capable of simultaneously mitigating a wide array of organic contaminants. Rather than merely capturing and transferring them to another phase, AOPs are able to mineralize organics. Semiconductor photocatalysis, e.g., irradiating titanium dioxide $\left(\mathrm{TiO}_{2}\right)$ nanoparticles at $\lambda<387 \mathrm{~nm}$ to produce $\mathrm{HO} \bullet$, is a promising AOP used to degrade aquatic environmental pollutants (Liu et al., 2008b; Zhang et al., 2007). Photocatalysis has demonstrated efficacy in treating organic contaminants such as disinfection byproducts (DBPs) and DBP precursors (Chin and Bérubé, 2005; Gerrity et al., 2008; Glauner et al., 2005; Hand 
et al., 1995; Kleiser and Frimmel, 2000; Liu et al., 2007; Mayer et al., 2014; Toor and Mohseni, 2007); microorganisms (Cho et al., 2005; Gerrity et al., 2008; Matsunaga et al., 1988; Ryu et al., 2008); toxic organics (Barreto et al., 1995; Orlov et al., 2007); and endocrine disruptors, pharmaceuticals and personal care products (Benotti et al., 2009; Kaneco et al., 2004; Thiruvenkatachari et al., 2007; Yu et al., 2006). However, no known full-scale municipal water treatment $\mathrm{TiO}_{2}$ photocatalysis operations currently exist.

One barrier to implementation is that, while $\mathrm{TiO}_{2}$ photocatalysis has the potential to mineralize organic contaminants, high levels of energy input are required to do so, e.g., $\geq 80 \mathrm{kWh} \mathrm{m}^{-3}$ (Gerrity et al., 2009; Mayer et al., 2014; Zhao et al., 2006). In comparison to organic destruction, the energy required to produce a UV dose of $40 \mathrm{~mJ} \mathrm{~cm}^{-2}$ ranges from approximately 0.003 to $0.025 \mathrm{kWh} \mathrm{m}^{-3}$ (Crittenden et al., 2012; USEPA, 2006b). For perspective, the USEPA-specified fluence for $4 \log$ inactivation of Cryptosporidium or Giardia is $22 \mathrm{~mJ} \mathrm{~cm}^{-2}$ and $186 \mathrm{~mJ} \mathrm{~cm}^{-2}$ for viruses. Though high-energy operations may be feasible for small-scale treatment of highly contaminated streams (e.g., localized destruction of organopesticides), they are not feasible for typical water treatment applications. Accordingly, a better understanding of the impact of low-energy AOPs on organics both macro-organics (e.g., natural organic matter) and micro-organics (e.g., estrogenic micropollutants) - is needed.

\subsection{Macro-organics: natural organic matter}

Natural organic matter (NOM) derives from decomposing plant and animal residues and microbial activity and is ubiquitous in surface and groundwaters (Krasner et al., 2006; Liu et al., 2008b; Stevenson, 1994). While its presence does not pose a direct threat to human health, it does introduce other concerns, most notably the production of potentially carcinogenic, mutagenic, genotoxic, and teratogenic DBPs when it reacts with oxidizing disinfectants such as chlorine (Hamidin et al., 2008; Richardson et al., 2007). The most common strategies for DBP mitigation target removal of precursor NOM prior to disinfection (Kulkarni and Chellam, 2010). Best available techniques include enhanced coagulation or softening, granular activated carbon (GAC), or membrane filtration (Kulkarni and Chellam, 2010; Liu et al., 2008b; Mayer et al., 2014; USEPA, 2006a). These practices are often sufficient to control DBP formation; however, the effectiveness of AOPs is also being investigated (Gerrity et al., 2009; Kleiser and Frimmel, 2000; Liu et al., 2008a, 2008b; Mayer et al., 2014; Mayer and Ryan, 2017; Philippe et al., 2010a, 2010b).

When operated at high-energy (e.g., $80 \mathrm{kWh} \mathrm{m}^{-3}$ ), AOPs such as photocatalysis can mineralize NOM. However, using more practical lower energy inputs yields incomplete oxidation, resulting in shifts toward smaller, less aromatic, and more hydrophilic moieties, which can exacerbate DBP formation in subsequent disinfection processes (Dotson et al., 2010; Gerrity et al., 2009; Liu et al., 2008a; Mayer et al., 2014; Sarathy and Mohseni, 2010). Thus, combinations of low-energy $\mathrm{TiO}_{2}$ photocatalysis (to break down complex organics) and other physicochemical operations such as filtration (to remove incomplete oxidation byproducts) may offer an effective alternative for controlling macro-organics and the related production of DBPs (Mayer and Ryan, 2017).

\subsection{Micro-organics: estrogenic compounds}

At the other end of the organic contaminant spectrum are micropollutants, including the steroidal estrogens estrone (E1), 17 $\beta$-estradiol (E2), estriol (E3), and 17 $\alpha$-ethynylestradiol (EE2). In water and wastewater, these estrogens are among the most common and most potent endocrine disrupting chemicals (Kuch and Ballschmiter, 2001; Rodriguez-Mozaz et al., 2004), and may have a significant impact on ecological and human 
health (Datson et al., 2003). Concern stems from hormonally-active compounds, such as estrogenic compounds, being linked to adverse effects on reproductive systems in both humans (Datson et al., 2003) and aquatic species (Kidd et al., 2007). Table S1 in the Supplementary Information (SI) shows key physicochemical estrogen characteristics.

Estrogenic micropollutants persist through conventional treatments such as coagulation and chlorine disinfection (Westerhoff et al., 2005). While conventional drinking water treatment processes such as coagulation and sedimentation may only remove a fraction of estrogenic compounds (approximately $\leq 50 \%$ ), AOPs can remove over 90\% (Chen et al., 2007; Westerhoff et al., 2005). Complete mineralization to $\mathrm{CO}_{2}$ occurs only with the use of high-energy inputs (Nomiyama et al., 2007). Alternatively, using low-energy inputs, partial oxidation, e.g., oxidation of hydroxyl groups to ketones, may proceed, thereby reducing the estrogenic activity of the compound without demanding the high-energy input required to achieve complete oxidation (Coleman et al., 2004; Ohko et al., 2002). Reduction in estrogenic activity is typically observed simultaneously with degradation of the parent estrogen, bypassing the need for molecular mineralization (Li Puma et al., 2010).

\subsection{Sequential low-energy $\mathrm{TiO}_{2}$ photocatalysis and filtration}

Using low-energy inputs, $\mathrm{TiO}_{2}$ photocatalysis is likely to cause incomplete oxidation. By itself, this transformation may not confer great benefits (and may even exacerbate DBP formation (Gerrity et al., 2009; Mayer et al., $\underline{2015}, \underline{2014})$ ). However, when used as a pretreatment for downstream processes, this conversion may offer advantages by harnessing multiple mechanisms of contaminant mitigation. In addition to photon-driven oxidation, which provides microbial inactivation and oxidation of organics, downstream filtration provides physical removal via adsorption and/or straining. Filter operation may also improve, e.g., extended filter life.

For removal of organic matter, granular activated carbon (GAC) filters are considered one of the best available technologies (USEPA, 2006a). However, the number of available GAC adsorption sites is finite, and GAC must be replaced or regenerated periodically using heat or acid treatment to re-activate the sites. This reactivation process increases costs, particularly for municipal systems with variable influent water quality. Use of lowenergy $\mathrm{TiO}_{2}$ photocatalysis ahead of GAC filters may improve filter operation while also efficiently removing NOM, which subsequently assists with DBP mitigation. Incomplete oxidation via low-energy AOPs yields smaller, less aromatic, and more hydrophilic organics (Lamsal et al., 2011; Liu et al., 2008b, 2008a; Mayer et al., 2014; Metz et al., 2011; Sarathy and Mohseni, 2010). The smaller size humic fractions generally adsorb more efficiently on GAC as the smaller molecules may be better able to access adsorbent surfaces (some humic substances are on the order of 4.7-33 $\AA$, whereas activated carbon may have pores widths $\leq 20 \AA$ ) ( Kilduff et al., 1996; Thurman, 1982).

Incomplete oxidation byproducts may also reduce membrane fouling due to removal or transformation of the major organic fraction linked to fouling (Liu, 2009). Membrane filtration can be hampered by operational issues such as membrane fouling caused by NOM adsorption or deposition, which is not satisfactorily controlled using conventional pretreatment methods such as coagulation/flocculation (Liu, 2009; Zularisam et al., 2006). Initial research suggests that $\mathrm{TiO}_{2}$ photocatalysis can effectively limit organic fouling on membranes by changing the physicochemical properties of the organic matter through removal and transformation of large, hydrophobic NOM compounds (Huang et al., 2008; Liu, 2009).

This study assessed the impact of low-energy photocatalysis on macro-organic matter (targeting partial NOM removal and improvement in downstream filtration processes) and estrogenic micro-organics (E1, E2, E3, and EE2). The specific objectives were to 1 ) assess removal of macro-organics (DOC, $U V_{254}$, and SUVA) at each stage of sequential low-energy photocatalysis followed by GAC or membrane filtration, 2) quantify changes in GAC or membrane filtration performance (bed lives or time to foul, respectively) using low-energy photocatalysis ahead 
of filtration, and 3) evaluate the removal of the micro-organics E1, E2, E3, and EE2 using low-energy photocatalysis.

\section{Materials and methods}

\subsection{Test water preparation}

All macro-organic test waters were prepared by dissolving technical-grade humic acid sodium salt (SigmaAldrich, St. Louis, MO) in Milli-Q water to obtain a concentration of approximately $5 \mathrm{mg} \mathrm{L}^{-1}$ dissolved organic carbon (DOC). In this study, DOC was used as a bulk measure of NOM quantity, while UV absorbance at $254 \mathrm{~nm}$ $\left(U_{254}\right)$ and specific UV absorbance (SUVA) were used as indicators of NOM character (i.e., aromaticity). SUVA was calculated by normalizing $U_{254}$ with respect to $D O C$. Each of these parameters has been used as a surrogate measure of NOM, and in modeling DBP formation potential (Chowdhury et al., 2009).

To avoid interference, micro-organic estrogen tests were performed separately from macro-organic carbon tests. The estrogens ( $\geq 97 \%$ purity E1, E2, E3, and EE2, Sigma-Aldrich) were pre-dissolved in HPLCgrade methanol $(99 \%$, Sigma-Aldrich, St. Louis, MO) for use as a stock solution. Synthetic water was prepared for each test by spiking the estrogens into Milli-Q water to achieve final concentrations of approximately $380 \mu \mathrm{g} \mathrm{L}^{-1}$ each. These concentrations were higher than typical environmental levels $\left(\mathrm{ng} \mathrm{L}^{-1}\right)$, but facilitated analysis of high degrees of removal. To negate co-solvent effects, the volumetric ratio of methanol stock to water was below $0.5 \%$ for all tests (Schwarzenbach et al., 2005): $2 \mathrm{~mL}$ estrogen stocks in methanol in $2 \mathrm{~L}$ water. The stock solution was mixed in a closed vessel on a stir plate for $12 \mathrm{~h}$ to ensure homogenous influent.

\subsection{Photocatalysis}

Fig. S1 in the SI illustrates the experimental approach. All UV and photocatalysis tests were performed in replicate ( $n=3-8$ independent experiments) using a bench-scale, batch-mode recirculating continuous flow system consisting of a 2-gal (7.57-L) stainless steel reservoir, Tetra Whisper ${ }^{\circ}$ air pump and stainless steel aeration wand, a stainless steel motorized inline pump, and a 17-W low-pressure UV-light (Aqua-Pure APUV2, $\lambda=254 \mathrm{~nm}, \mathrm{I}_{\mathrm{o}}=5 \mu \mathrm{W} \mathrm{cm}{ }^{-2}$ at $1 \mathrm{~m}$ in air at room temperature) connected with stainless steel piping and fittings. The continuously recirculating system flowrate was maintained at approximately $1.5 \mathrm{gpm}\left(8.18 \mathrm{~m}^{3} \mathrm{~d}^{-1}\right)$ using a stainless steel ball valve. The UV lamp was allowed to warm for 5 min prior to initiating experiments.

Titanium (IV) dioxide (Aeroxide ${ }^{\circ} \mathrm{P} 25 \mathrm{TiO}_{2}$, approximately $80 \%$ anatase and $20 \%$ rutile, $\geq 99.5 \%$ trace metals basis, Sigma-Aldrich) with an average primary particle size of $21 \mathrm{~nm}$ (which form aggregates several hundred $\mathrm{nm}$ in size) was added as a one-time addition to the influent water at a concentration of $0.1 \mathrm{~g} \mathrm{~L}^{-1}$ for all photocatalysis tests. Optimum $\mathrm{TiO}_{2}$ loading is reportedly $0.05-1 \mathrm{~g} \mathrm{~L}^{-1}$, whereas higher concentrations can negatively impact estrogen removal (Sornalingam et al., 2016). In this study, preliminary tests comparing $0.1,0.3,0.5$, and $1 \mathrm{~g} \mathrm{~L}^{-1} \mathrm{TiO}_{2}$ demonstrated that $0.1 \mathrm{~g} \mathrm{~L}^{-1}$ provided the greatest photocatalytic enhancement beyond physical contaminant removal via adsorption on the $\mathrm{TiO}_{2}$ surface (data shown in the $\mathrm{SI}$ ). $\mathrm{The}^{\mathrm{TiO}} 2$ photocatalysis experiments were run at low-level AOP energy (electrical) inputs of 1, 2, and $5 \mathrm{kWh} \mathrm{m}^{-3}$ to encourage partial oxidation. Additionally, $80 \mathrm{kWh} \mathrm{m}^{-3}$ tests were used as a high energy, or near complete oxidation, control. The energy inputs were achieved by treating the water samples in the recirculating reactor for varying time intervals. At all energy levels, UV-only (no $\mathrm{TiO}_{2}$ added) tests were performed in parallel to photocatalysis to assess the impact of UV photolysis by itself. Dark adsorption, i.e., $\mathrm{TiO}_{2}$-only $\left(0 \mathrm{kWh} \mathrm{m}^{-3}\right)$, tests were performed as controls to assess physical removal of contaminants due to adsorption onto the $\mathrm{TiO}_{2}$ surface. Photocatalysis samples were collected for analysis of DOC, UV 254 , and SUVA or E1, E2, E3, and EE2. Following photocatalysis and in-line filtration to remove $\mathrm{TiO}_{2}$ aggregates ( $0.45 \mu \mathrm{m}$ PTFE syringe filters, Agela Technologies, Wilmington, DE), the macro-organic waters were treated with lab-scale GAC or membrane filtration, as illustrated in Fig. S1. 


\subsection{Filtration}

\subsubsection{GAC filtration}

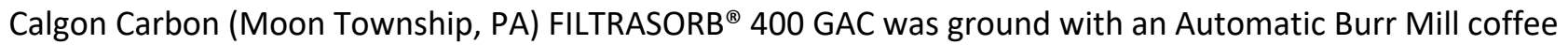
grinder and sieved using No. 170 and No. 140 sieves (Thermo Fisher Scientific, Hampton, NH) to obtain a particle size between 90 and $106 \mu \mathrm{m}$. This particle size was scaled to the column size in accordance with recommendations based on the dispersed-flow pore surface diffusion model (DFPSDM) (ASTM, 2014; Crittenden et al., 1986). The sieved GAC was rinsed for $15 \mathrm{~min}$, which was sufficient time to achieve no change in DOC in the rinse water. The GAC was stored in Milli-Q water until use in rapid small-scale column tests (RSSCTs).

The RSSCTs were conducted in accordance with American Society for Testing and Materials D6586-03 (ASTM, 2014) using $1.1 \mathrm{~cm}$ diameter $\times 60 \mathrm{~cm}$ long glass columns (Ace Glass, Vineland, NJ), $5 \mathrm{~mm}$ beads (Ace Glass), fine glass wool, $350 \mu \mathrm{m}$ mesh screens with polytetrafluoroethylene (PTFE) support rings, and approximately $27 \mathrm{~g}$ (wet weight) of GAC. Column arrangement was similar to that described by Daugherty (2011). A model NE-9000 peristaltic pump (New Era Pump Systems, Inc., Farmingdale, NY) with PTFE tubing delivered water to the columns at a flowrate of $7.5 \mathrm{~mL}$ min-1. The columns were backwashed and rinsed with Milli-Q water prior to use to ensure that carbon losses from the column were $\leq 0.3 \mathrm{mg} \mathrm{L}-1 \mathrm{DOC}$. Column effluent samples were collected every $5 \mathrm{~min}$ for the first $40 \mathrm{~min}$, with post-breakthrough $(\mathrm{C} / \mathrm{Co}=5 \%)$ sample collection tapering off until the effluent concentration was approximately constant ( $<5 \%$ concentration change between sampling points).

\subsubsection{Membrane filtration}

The membrane filtration testing system consisted of an EMD Millipore 5-L dispensing pressure vessel (Model XX6700P05, Darmstadt Germany), EMD Millipore 5122 Amicon Stirred Cell (Model 8050), top-loading balance (Model MS3002S, Mettler-Toledo, Inc., Columbus, $\mathrm{OH}$ ), and $0.1 \mu \mathrm{m}$ pore size Durapore polyvinylidene fluoride membrane filter discs. Effluent from the photocatalysis experiments was added to the vessel, which was pressurized to 30 psi with nitrogen gas. Membrane fouling was assessed by flow of permeate passing through the membrane under constant pressure, quantified as the cumulative mass of permeate collected. Permeate mass was recorded every $10 \mathrm{~s}$ until the membrane had fouled, as signified by negligible water passage across the membrane (i.e., negligible change in the mass of permeate). Filter run times were assessed as described in the SI.

\subsection{Analytical measurements}

All macro-organic samples were acidified with $\mathrm{HCl}$, filtered using sterile $0.45 \mu \mathrm{m}$ PTFE syringe filters (Agela Technologies, Wilmington, DE), and analyzed for DOC and UV 254 in accordance with USEPA Method 415.3 (Potter and Wimsatt, 2005). A Thermo Scientific (Waltham, MA) Genesys 20 spectrophotometer was used to measure

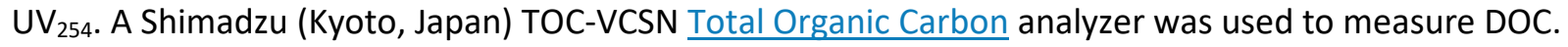
All glassware used for macro-organic testing was acid washed with $\mathrm{HCl}$ and baked at $550{ }^{\circ} \mathrm{C}$ prior to use.

For micro-organic estrogen analysis, samples were filtered using sterile $0.22 \mu \mathrm{m}$ PTFE syringe filters (Agela Technologies) to remove $\mathrm{TiO}_{2}$ and minimize clogging in subsequent liquid chromatographymass spectrometry (LC-MS) analysis. A Shimadzu LCMS-2020 equipped with a Phenomenex Kinetex $5 \mu$ EVO C18 100A $100 \times 3.0 \mathrm{~mm}$ reversed phase column was operated in negative ion mode for quantification of the estrogens. The SI provides additional details on the LC-MS method. In the case of non-detects, the minimum detection limit ( $\mathrm{MDL}, 4-16 \mu \mathrm{g} \mathrm{L}^{-1}$ ) was used to calculate estrogen removals. All glassware used for microorganics was washed with soap and water and rinsed three times in lab-grade methanol. Between uses, the amber sample collection vials were rinsed in deionized water, sonicated in methanol for 20 min, dried, and then baked at $550{ }^{\circ} \mathrm{C}$ for $1 \mathrm{~h}$. 


\subsection{Data analysis and statistics}

Rates of organic degradation were assessed using pseudo-first order kinetic modeling of target removal with respect to treatment time. The electrical energy per order of magnitude removal (EEO), a commonly used metric enabling comparisons amongst treatment processes (Bolton et al., 1996), was calculated for each treatment scenario using first order kinetic terms, as shown by Equation (1) (Gerrity et al., 2010).(1)

$$
E E O=\frac{\ln (0.1)}{k}=\frac{\ln (0.1)}{\text { slopeofenergyinput }\left(\mathrm{kWhm}^{-3}\right) \mathrm{vs} \cdot \ln \left(\mathrm{C} / \mathrm{C}_{\mathrm{o}}\right)}
$$

Datasets were assessed for statistical differences using one-way ANOVA (results and additional description in the SI), followed by post-hoc multiple comparison using the Tukey test. The Kolmogorov-Smirnov test with Dallal-Wilkinson-Lilliefor corrected $p$ values (minimum $n=5$ ) was used to gauge normality, and showed that most of the analyzable data followed a normal distribution. Assuming Gaussian distributions, Pearson correlation coefficients were computed to assess correlations between datasets. Differences in kinetic degradation rates were evaluated using sum of squares tests. All statistics were performed using GraphPad Prism 6 software at a significance level of $\alpha=0.05$. Microsoft Excel 2016 was used to plot all results.

\section{Results and discussion}

\subsection{Macro-organic photocatalysis}

Percent reduction of $\mathrm{DOC}, \mathrm{UV}_{254}$, and SUVA during UV photolysis and $\mathrm{TiO}_{2}$ photocatalysis increased with increasing system energy input (Fig. 1). At low-energy inputs $\left(\leq 5 \mathrm{kWh} \mathrm{m}^{-3}\right), \mathrm{UV}$ alone did not effectively reduce the concentration of DOC, nor did it reduce aromaticity. However, $80 \mathrm{kWh} \mathrm{m}^{-3} \mathrm{UV}$-only treatment offered significant removal of DOC coupled with shifts in its character, as signified by significant improvements in $\mathrm{UV}_{254}$ and SUVA removal (Tukey $\mathrm{p}<0.0001$ ). The $\mathrm{SI}$ includes a full summary of study statistics. Photolytic degradation of the macro-organics followed pseudo-first order kinetics, with $U_{254}$ degrading at a significantly higher rate than DOC (nearly 5 times faster, as shown in Fig. $2, p<0.0001$ ).
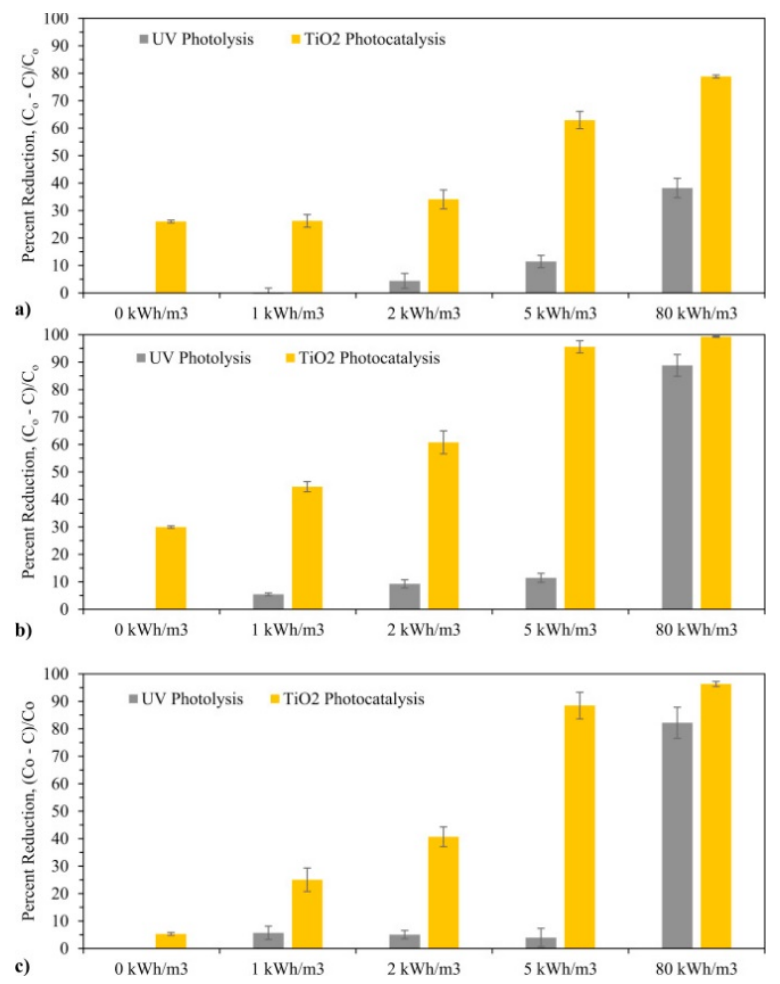
Fig. 1. Percent reduction of a) DOC, b) UV 254 , and c) SUVA using varying energy inputs for UV photolysis and $\mathrm{TiO}_{2}$ photocatalysis $\left(0.1 \mathrm{~g} \mathrm{~L}^{-1} \mathrm{TiO}_{2}\right)$ treatments. Bars represent the mean removal for replicate experiments $(n=3-6)$ and error bars indicate \pm 1 standard deviation.
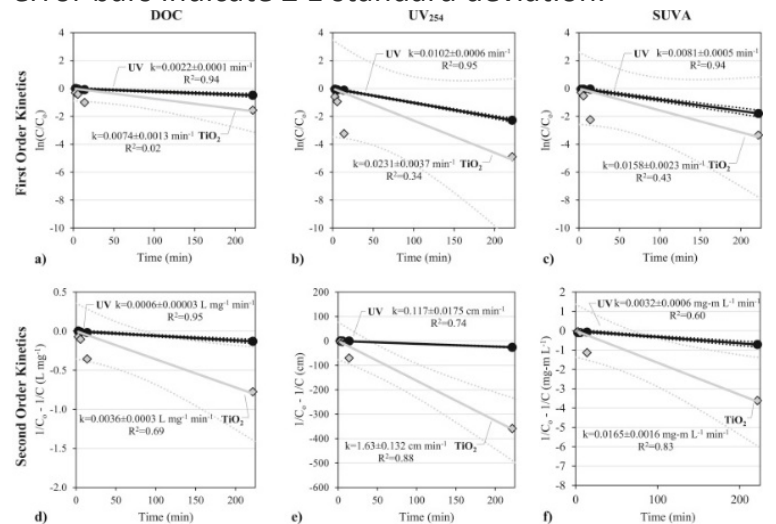

Fig. 2. Organic degradation profiles for varying levels of treatment using UV photolysis $(\bullet)$ or $\mathrm{TiO}_{2}$ photocatalysis $\left({ }^{\circ}\right)$ $\left(0.1 \mathrm{~g} \mathrm{~L}^{-1} \mathrm{TiO}_{2}\right)$. The points represent the mean values of replicate experiments $(n=3-6)$. The solid lines show best-fit linear regression with zero intercept models with associated rate constants $(k) \pm 95 \%$ confidence intervals. The dotted lines show the $95 \%$ confidence intervals. Plots a through c show pseudo-first order models for a) DOC, b) UV 254 , and c) SUVA. Plots d through $\mathrm{f}$ show second order models for d) DOC, e) UV 254 , and f) SUVA. For UV photolysis, pseudo-first order kinetics provided strong fits to the data, whereas for $\mathrm{TiO}_{2}$ photocatalysis, second order kinetics were more suitable.

The addition of $\mathrm{TiO}_{2}$ yielded significantly higher rates of macro-organic degradation compared to UV photolysis (Fig. $2, p<0.007$ ). Of note, while macro-organic degradation was better characterized by first order kinetics for UV photolysis, Fig. 2 shows that second-order kinetics provided a much better fit for $\mathrm{TiO}_{2}$ photocatalytic degradation. The improvements in macro-organic degradation using photocatalysis are further illustrated in Fig. 1, which shows significantly greater DOC, UV 254 , and SUVA removal at each energy level using photocatalysis versus UV alone. Process EEOs clearly demonstrated that $\mathrm{TiO}_{2}$ photocatalysis substantially improved degradation of macro-organics in comparison to photolysis treatment (Fig. 3 ).

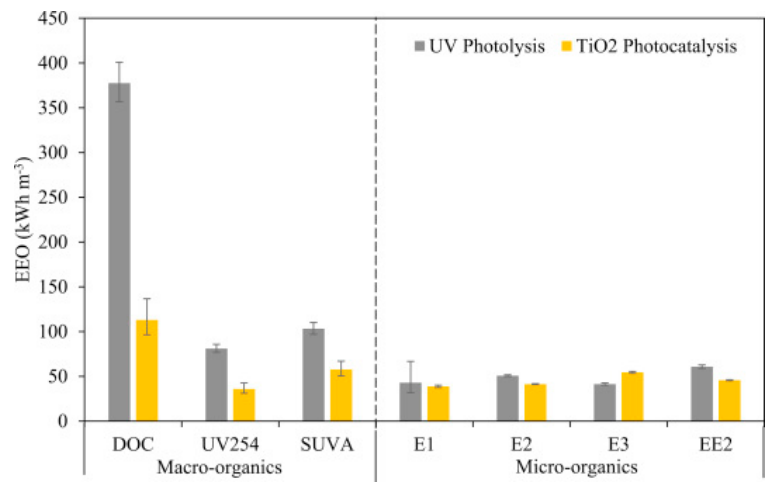

Fig. 3. Comparison of electrical energy efficiency per order magnitude (EEO) for the macro-organics and micro-organics using UV photolysis compared to $\mathrm{TiO}_{2}$ photocatalysis. Values were calculated based on first order kinetic degradation modeling (using $k \pm 95 \%$ confidence interval), in accordance with the EEO figure-of-merit definition (Bolton et al., 1996).

Significant improvements beyond dark adsorption alone were observed for photocatalytic degradation of DOC using energy inputs $\geq 2 \mathrm{kWh} \mathrm{m}^{-3}$ (Tukey $<0.03$ ). $U V_{254}$ and SUVA reduction improved significantly beyond dark adsorption for energy inputs $\geq 1 \mathrm{kWh} \mathrm{m}^{-3}$ (Tukey $\mathrm{p}<0.0001$ ), signifying changes in aromaticity prior to mineralization. For $\mathrm{UV}_{254}$ and SUVA, $80 \mathrm{kWh} \mathrm{m}^{-3}$ did not significantly improve removal beyond that achieved using $5 \mathrm{kWh} \mathrm{m}^{-3}$ (Tukey $p>0.36$ ). Thus, while additional mineralization is possible using $80 \mathrm{kWh} \mathrm{m}^{-3}$, as signified by $79 \%$ DOC removal, the vast majority of the aromatic portion was oxidized using a relatively low-energy input 
of $5 \mathrm{kWh} \mathrm{m}^{-3}$ ( $96 \%$ and $88 \%$ removal of $\mathrm{UV}_{254}$ and SUVA, respectively). Accordingly, the photocatalytic rate of $U V_{254}$ reduction was significantly greater than DOC (three orders of magnitude higher, Fig. 2, $\mathrm{p}<0.0001$ ).

\subsection{Macro-organic filtration}

In addition to the direct removal (DOC) and shifts in character (aromaticity, i.e., $\mathrm{UV}_{254}$, SUVA) of macro-organic matter during low-energy photocatalytic treatment, these changes in water quality improved the operation of subsequent GAC and membrane filtration processes.

\subsubsection{GAC filtration}

Normalized UV 254 absorbance of the GAC RSSCT effluent versus bed volumes treated is shown in Fig. 4. As illustrated, the number of bed volumes treated prior to breakthrough (defined as $A / A_{\circ}=5 \%$ ) significantly increased beyond GAC filtration alone using $2 \mathrm{kWh} \mathrm{m}^{-3}$ photocatalysis (Tukey $p=0.0006$ ), whereas no improvement was observed using $1 \mathrm{kWh} / \mathrm{m}^{3}$ photocatalysis, (Tukey $\mathrm{p}=0.9217$ ). Based on the mean values of triplicate experiments, $2 \mathrm{kWh} \mathrm{m}^{-3}$ photocatalysis extended the filter bed life by $340 \%$ compared to no photocatalysis pretreatment (direct filtration) and $266 \%$ compared to $1 \mathrm{kWh} \mathrm{m}^{-3}$ photocatalysis. This is consistent with the significant improvement in DOC reduction observed using $2 \mathrm{kWh} \mathrm{m}^{-3}$ (Fig. 1). No macroorganic breakthrough was recorded for the $5 \mathrm{kWh} \mathrm{m}^{-3}$ treatment during the 200 bed volume test period. Thus, high-energy $80 \mathrm{kWh} \mathrm{m}^{-3}$ was not tested in the RSSCTs as similar results were anticipated based on significant DOC removal using this photocatalysis energy input. The associated DOC breakthrough curves, exhibiting similar trends, are shown in the SI.

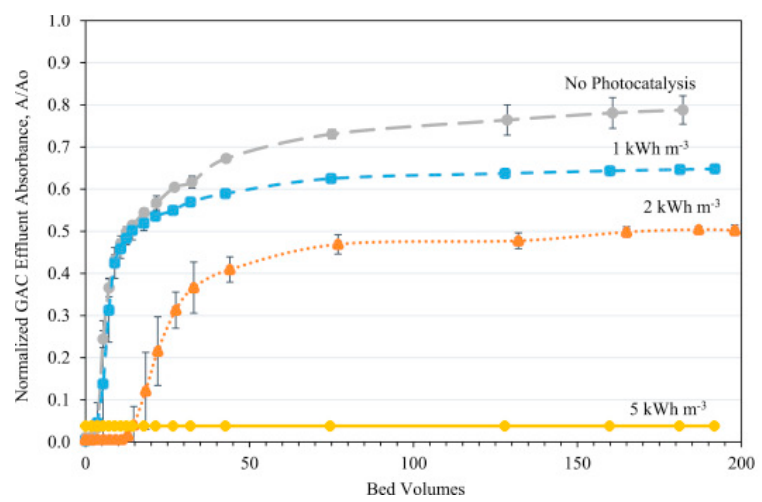

Fig. 4. Granular activated carbon (GAC) filter performance showing the averages of triplicate tests for effluent $U_{254}$ breakthrough curves for samples treated with varying low-energy input $\mathrm{TiO}_{2}$ photocatalysis coupled with GAC filtration. Error bars show \pm 1 standard deviation; some are too small to see clearly.

\subsubsection{Membrane filtration}

Mass of the filter permeate treated over time was used as an indicator of filter performance, as shown in Fig. 5. As illustrated, significantly reduced fouling was observed at $1 \mathrm{kWh} \mathrm{m}^{-3}$ compared to the no photocatalysis sample (Tukey $p<0.0001$ ), which was consistent with significant reduction of $U_{254}$ and SUVA at 1 kWh $\mathrm{m}^{-3}$ (Fig. 1). Using 1, 2, and $5 \mathrm{kWh} \mathrm{m}^{-3}$ energy inputs, $\mathrm{TiO}_{2}$ photocatalysis pretreatment was able to extend filter run time by 30,36 , and 47 fold, respectively, in comparison to direct filtration (additional description in the SI). Thus, coupling the partial oxidation and change in character provided by low-energy $\mathrm{TiO}_{2}$ photocatalysis with membrane filtration reduced membrane fouling, thereby extending the life of the filter. Pearson correlation statistics suggest that changes in both organic quantity (DOC) and character $\left(\mathrm{UV}_{254}\right)$ contributed to improvements in run time, with $\mathrm{UV}_{254}$ having a more significant correlation ( $r$ value $=-0.9173$ and -0.9562 and $p$ value $=0.0282$ and 0.0109 for DOC and $U_{254}$, respectively). 


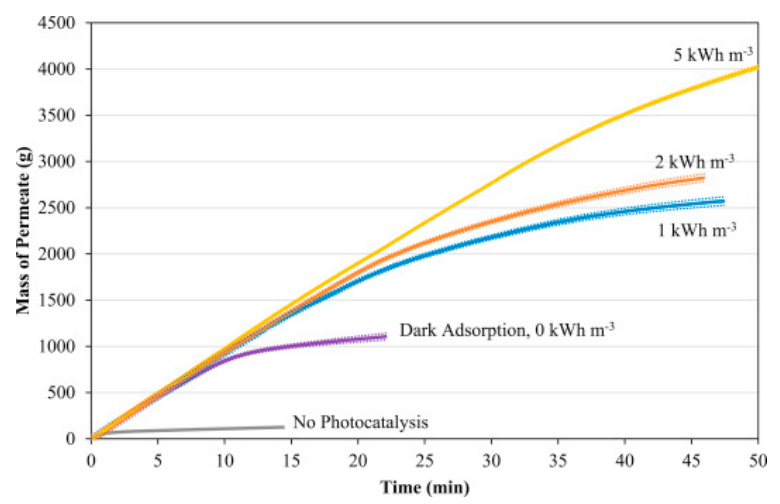

Fig. 5. Membrane filter performance showing the averages of triplicate tests assessing mass of the permeate as a function of time using varying low-energy input $\mathrm{TiO}_{2}$ photocatalysis coupled with microfiltration (dotted lines show $\pm 95 \%$ confidence intervals).

As organics degrade through partial oxidation caused by low-energy $\mathrm{TiO}_{2}$ photocatalysis, there is potential for increases in NOM in the microfiltration permeate as smaller compounds pass through unabated. Here, quality of the membrane permeate improved with increasing levels of photocatalytic treatment (levels of both DOC and $\mathrm{UV}_{254}$ in the permeate decreased), generally in step with improved influent quality. Specifically, percent DOC removal across the membrane did not change significantly with treatment (ANOVA, $p=0.9091$ ). Using $5 \mathrm{kWh}$ $\mathrm{m}^{-3}, \mathrm{UV}_{254}$ was not detected in the filtered samples (which differed significantly from other levels of energy input, Tukey $p<0.0263$ ); levels of $U V_{254}$ in the effluent using other energy inputs did not differ significantly (Tukey $p>0.9712$ ).

\subsection{Micro-organic photocatalysis: degradation of estrogens}

As shown in Fig. 6 , using $80 \mathrm{kWh} \mathrm{m}^{-3}$ of UV alone provided $\geq 95 \%$ removal of each estrogen (estrogens were not detected in the treated samples; thus the MDL was used to calculate removal). The photolysis profiles of E2, E3, and EE2 were similar for the conditions tested, but E1 degradation was much faster, in agreement with results reported by Li Puma et al. (2010). For E1, even relatively low UV inputs provided high levels of removal, with no significant improvement using energy inputs greater than $2 \mathrm{kWh} \mathrm{m}^{-3}$ (93\% removal, Tukey $\left.\mathrm{p}>0.81\right)$. Rapid E1 degradation to levels at or near the MDL led to an extremely poor fit using pseudo first-order kinetic modeling (Fig. 7; zero and second order kinetics also provided poor fits). However, E2, E3, and EE2 demonstrated strong pseudo first-order behavior, consistent with most reports of photodegradation of estrogenic steroidal hormones (Sornalingam et al., 2016). For these three estrogens, the overall rate of photolytic removal varied significantly ( $p<0.0001$; although the difference is likely minimal in application), following the trend $k_{E 3}>k_{E 2}>k_{E E 2}$. Li PUma et al. (2010) reported the same trend. However, relative rates have most often been reported as $k_{E 1}>k_{E E 2}>k_{E 2}>k_{E 3}$ for both photolysis and $\mathrm{TiO}_{2}$ photocatalysis (Sornalingam et al., 2016).

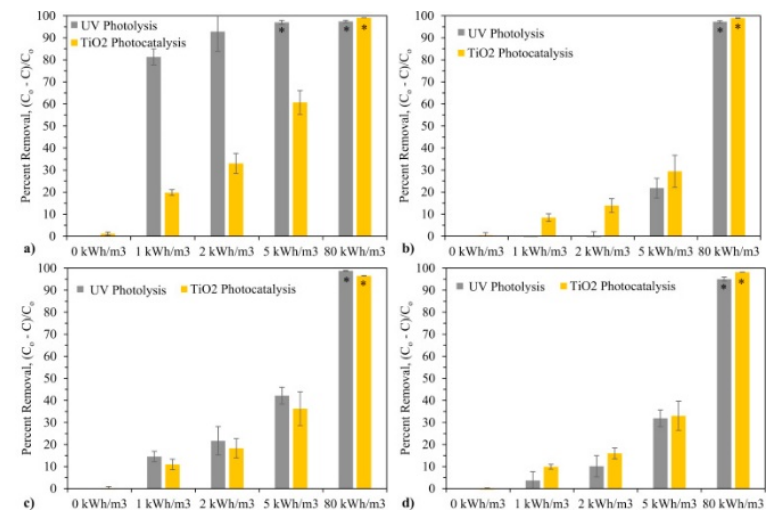


Fig. 6. Percent reduction of a) E1, b) E2, c) E3, and d) EE2 estrogens as a function of energy inputs for UV photolysis and $\mathrm{TiO}_{2}$ photocatalysis $\left(0.1 \mathrm{~g} \mathrm{~L}^{-1} \mathrm{TiO}_{2}\right)$ treatments. Bars represent the mean reduction in replicate experiments $(n=3-8)$ and error bars indicate \pm 1 standard deviation. Bars denoted with an asterisk $(*)$ signify datasets in which all treated samples were below the minimum detection limit (MDL), in which case removals were calculated using the MDL (4-16 $\left.\mu \mathrm{g} \mathrm{L}^{-1}\right)$ as the final concentration.
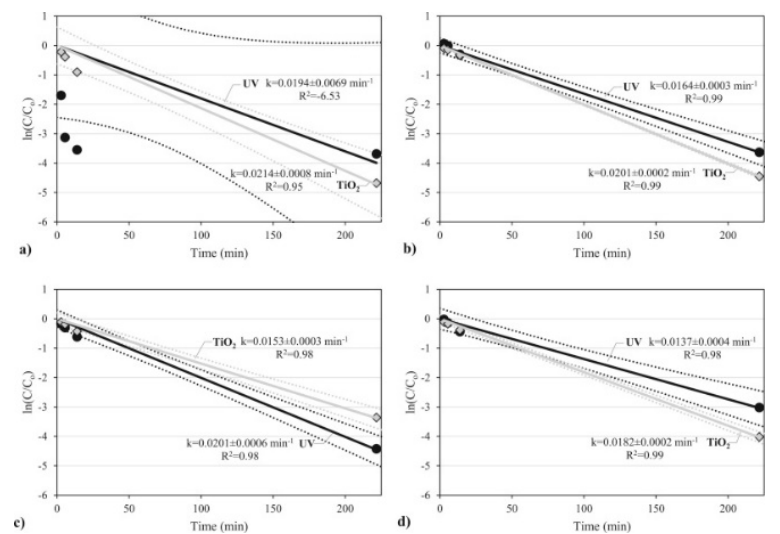

Fig. 7. Estrogen degradation profiles for varying levels of UV photolysis $(\bullet)$ or $\mathrm{TiO}_{2}$ photocatalysis $\left({ }^{\circ}\right)\left(0.1 \mathrm{~g} \mathrm{~L}^{-1} \mathrm{TiO}_{2}\right)$ treatment for a) E1, b) E2, c) E3, and d) EE2. The points represent the mean values of replicate experiments $(n=3-8)$. The solid lines show best-fit linear regression with zero intercept models with associated pseudo-first order kinetic rate constants $(k) \pm 95 \%$ confidence intervals. The dotted lines show the $95 \%$ confidence intervals.

Estrogen removals using $\mathrm{TiO}_{2}$ photocatalysis are compared to UV photolysis in Fig. 6. Estrogens E1, E2, E3, and EE2 are moderately hydrophobic weak acids present as uncharged molecules at neutral pH levels (Hanselman et al., 2003). As such, they did not adsorb to $\mathrm{TiO}_{2}$ to a large extent, as shown by the dark adsorption $0 \mathrm{kWh}$ $\mathrm{m}^{-3}$ controls. For $\mathrm{E} 3$ and EE2, the UV and photocatalysis results for given energy inputs were not statistically different (Tukey $p>0.08$, with the exception of $5 \mathrm{kWh} \mathrm{m}^{-3}$, wherein photocatalysis was worse than UV alone), indicating that photocatalysis did not improve micro-organic removal. In the case of E2, low-energy inputs of 1 and $2 \mathrm{kWh} \mathrm{m}^{-3}$ did not improve removal beyond dark adsorption on the $\mathrm{TiO}_{2}$ surface (Tukey $\mathrm{p}>0.47$ ). However, at these energy levels, photocatalysis did enhance E2 degradation beyond photolysis alone (Tukey $p<0.0007$ ), whereas there was no significant difference between treatments at higher energy inputs (Tukey $p>0.99$ ).

In the case of E1, photocatalysis significantly decreased removals (Tukey $p<0.0001$ ), with the exception of the high-energy $80 \mathrm{kWh} \mathrm{m}^{-3}$ treatment, where reductions due to photocatalysis were the same as using photolysis. Accordingly, for contaminants that are efficiently photodegraded, the addition of suspended $\mathrm{TiO}_{2}$ may actually detract from removal as UV transmittance declines due to blocking/refraction caused by the $\mathrm{TiO}_{2}$ nanoparticles. This effect has been hypothesized as the basis for decreased virus inactivation using a collimated beam photocatalysis reactor (Gerrity et al., 2008). In contrast, Li Puma et al. (2010) observed improvements in degradation of E1, E2, E3, and EE2 using photocatalysis. A higher $\mathrm{TiO}_{2}$ dose of $0.4 \mathrm{~g} \mathrm{~L}^{-1}$ was used in their study, whereas a dose of $0.1 \mathrm{~g} \mathrm{~L}^{-1}$ was used here. Zhang et al. (2007) reported that E1 and E2 removal increased with increasing $\mathrm{TiO}_{2}$ dose from 0.5 to $2 \mathrm{~g} \mathrm{~L}^{-1}$. Thus, it is possible that the higher $\mathrm{TiO}_{2}$ dose provided sufficient $\mathrm{HO} \bullet$ such that a tipping point between decreased photolysis and increased photocatalysis was achieved.

Considering all data points, the overall pseudo-first order rate of photocatalytic degradation followed the trend $k_{E 1}>k_{E 2}>k_{E E 2}>k_{E 3}($ Fig. 7, Tukey $p<0.0001)$. The resulting EEOs ( $\underline{\text { Fig. } 3}$ ) indicate that photocatalysis improved treatment efficiency for all targeted organics except E3. Of note, while the EEO values for E1 indicate slight photocatalytic improvement, E1 demonstrated a poor fit to the pseudo-first order kinetic model, which introduced considerable uncertainty in subsequent calculations (as reflected by the error bars in Fig. 3). Although EEO values facilitate process comparisons, as they are independent of the nature of the treatment 
system, experimental conditions influence EEO. For example, the experimentally-determined EEO for UV treatment of E1 was 42.9 in this study, whereas Sarkar et al. (2014) reported 14.2. For greater perspective, Fig. S4 in the SI shows EEO values for E1 determined in this study in comparison to EEOs reported using a range of AOPs.

The ratios of EEO $\mathrm{Tio2}_{\mathrm{T}}$ :EEOuv were 0.91 for E1, 0.81 for E2, 1.31 for E3, 0.75 for EE2, 0.30 for DOC, 0.44 for $\mathrm{UV}_{254}$, and 0.56 for SUVA. This indicates that photocatalysis offers greater improvement in degradation of macroorganics in comparison to micro-organics. As photolysis alone is not very effective in degrading DOC (Fig. 1), it makes sense that AOPs offer greater opportunities for improvement.

The degree of oxidative degradation of micro-organics (pharmaceutical and personal care products) has previously been correlated to degradation of macro-organics - specifically reductions in $U_{254}$ (Gerrity et al., 2010; Wert et al., 2009). In this study, $U_{254}$ removal using UV alone demonstrated strong positive correlations to all other target contaminants $(p<0.01)$ except $E 1$, removal of which did not correlate to any other contaminant. Conversely, for $\mathrm{TiO}_{2}$ photocatalysis, removal of each estrogen correlated strongly to the other estrogens, but not to macro-organic removal (full statistics shown in the $\mathrm{SI}$ ).

Although there is no universal reaction pathway for the phototransformation of estrogens (Sornalingam et al., 2016), byproducts can have important ramifications. For the incomplete oxidation scenarios encountered during low-energy photocatalysis, the byproducts and their relative threats compared to parent compounds are also relevant (Rosenfeldt and Linden, 2004). Ohko et al. (2002) used a combination of lab experiments and theoretical calculations of frontier electron densities to demonstrate that $\mathrm{TiO}_{2}$ photocatalytic degradation of $\mathrm{E} 2$ is initiated by oxidation of the phenol moiety. The resultant intermediate degradation byproducts, $10 \varepsilon-17 \beta-$ dihydroxy-1,4-estradien-3-one and testosterone-like species, exhibited negligible estrogenic activity (Ohko et al., 2002). Other steroidal estrogens, including E1, E3, and EE2, would be expected to degrade in a similar manner, wherein estrogenic activity is almost completely lost in the first step of photocatalytic oxidation, oxidation of the phenol moiety (Ohko et al., 2002). Similarly, Benotti et al. (2009) observed rapid loss of estrogenicity in a pilotscale photocatalytic membrane reactor, with no byproducts exhibiting estrogenicity.

\section{Conclusions}

Advanced oxidation processes such as $\mathrm{TiO}_{2}$ photocatalysis have considerable potential for mitigating recalcitrant water and wastewater contaminants. However, the high energy and/or chemical inputs needed to mineralize target organics often make AOPs infeasible for adoption in typical water treatment settings. Effective AOP implementation relies on viable strategies to reduce energy demands while meeting treatment objectives.

In this study, low-energy photocatalytic treatment improved the degradation rate of most target organic contaminants, but not all. Compared to UV photolysis alone, $\mathrm{TiO}_{2}$ photocatalysis substantially improved removal of the aromatic macro-organic fraction (assessed as $U V_{254}$ ). The rate of $U V_{254}$ removal was significantly higher than DOC, with a pseudo-first order rate constant ( $\left.k_{u v 254}\right)$ three orders of magnitude higher than $k_{\text {Doc. }}$ However, photocatalytic degradation of the estrogens was approximately equivalent to photolysis (demonstrated by similar EEOs), or somewhat worse in the cases of E1 and E3.

The incomplete oxidation of organics stemming from low-energy AOP operation can successfully mitigate some micro-organic contaminants. For example, the initial step in the photocatalytic degradation of estrogens oxidation of the phenol moiety - ostensibly reduces estrogenicity in step with degradation of the parent compound (Ohko et al., 2002). However, incomplete oxidation may exacerbate other issues, e.g., increasing DBP formation due to the production of more reactive lower molecular weight, less aromatic macro-

organic byproducts. 
Accordingly, multi-barrier treatment strategies such as pairing low-energy AOP treatments with other processes, e.g., filtration, may confer treatment advantages. AOP-filtration sequences could help control organic contaminants, and also alleviate other negative impacts associated with NOM in drinking water, including DBP formation, degraded aesthetics (color, taste, and odor) (Liu et al., 2008b), and interference with other water treatment processes such as activated carbon adsorption, membrane filtration, and ion exchange (Karanfil et al., 1999; Liu et al., 2008b; Yoon et al., 1998). In this study, low-energy photocatalysis significantly improved downstream GAC and microfiltration membrane operation by extending filter life while maintaining effluent quality.

Future assessments should evaluate more realistic water matrices, in which complex interactions between macro- and micro-organics likely influence contaminant removals. For example, sorption of hydrophobic estrogens to NOM can strongly influence behavior of these compounds in the environment and during treatment. Thus, if photocatalysis yields more hydrophilic species, less estrogen removal may be observed stemming from less adsorption on NOM and subsequent removal during filtration. Alternately, Yamamoto et al. (2003) suggested that hydrophobic interactions were not the dominant mechanism for estrogen sorption on NOM, but that the phenolic groups of steroidal estrogens (and the related interactions between $\pi$-electrons and hydrogen bonds) may be more important. Accordingly, loss of these groups during photocatalysis could also impede their co-removal with NOM during filtration. It follows that the complex interactions between macroand micro-organics and their relevance to paired AOP-filtration operations is of great interest in future research studies.

\section{Acknowledgements}

Support for this project was provided by the National Science Foundation and the Water Equipment and Policy Industry/University Cooperative Research Center (I/UCRC) through the Collaborative Opportunity for Research Between Centers (CORBI) program, Grant No. IIP-0968844. NW was funded by the Marquette University Opus College of Engineering Undergraduate Research Program. The authors acknowledge the use of the LC-MS from Marquette University, funded by the GHR Foundation.

\section{References}

\section{ASTM, 2014 ASTM D6586-03 Standard Practice for the Prediction of Contaminant Adsorption on GAC in} Aqueous Systems Using Rapid Small-scale Column Tests (2014), 10.1520/D6586-03R08.2

Barreto et al., 1995 R.D. Barreto, K.A. Gray, K. Anders Photocatalytic degradation of methyl-tert-butyl ether in TiO2 slurries: a proposed reaction scheme Water Res., 29 (1995), pp. 1243-1248

Benotti et al., 2009 M.J. Benotti, B.D. Stanford, E.C. Wert, S.A. Snyder Evaluation of a photocatalytic reactor membrane pilot system for the removal of pharmaceuticals and endocrine disrupting compounds from water Water Res., 43 (2009), pp. 1513-1522, 10.1016/i.watres.2008.12.049

Bolton et al., 1996 J.R. Bolton, K.G. Bircher, W. Tumas, C.A. Tolman Figures-of-merit for the technical development and application of advanced oxidation processes J. Adv. Oxid. Technol., 1 (1996), pp. 1317, 10.1515/jaots-1996-0104

Chen et al., 2007 C.-Y. Chen, T.-Y. Wen, G.-S. Wang, H.-W. Cheng, Y.-H. Lin, G.-W. Lien Determining estrogenic steroids in Taipei waters and removal in drinking water treatment using high-flow solid-phase extraction and liquid chromatography/tandem mass spectrometry Sci. Total Environ., 378 (2007), pp. 352-365, 10.1016/j.scitotenv.2007.02.038

Chin and Bérubé, 2005 A. Chin, P.R. Bérubé Removal of disinfection by-product precursors with ozone-UV advanced oxidation process Water Res., 39 (2005), pp. 2136-2144, 10.1016/i.watres.2005.03.021 
Cho et al., 2005 M. Cho, H. Chung, W. Choi, J. Yoon Different inactivation behaviors of MS-2 phage and Escherichia coli in TiO2 photocatalytic disinfection Appl. Environ. Microbiol., 71 (2005), pp. 270-275

Chowdhury et al., 2009 S. Chowdhury, P. Champagne, P.J. McLellan Models for predicting disinfection byproduct (DBP) formation in drinking waters: a chronological review Sci. Total Environ., 407 (2009), pp. 4189-4206, 10.1016/i.scitotenv.2009.04.006

Coleman et al., 2004 H.M. Coleman, E.J. Routledge, J.P. Sumpter, B.R. Eggins, J.A. Byrne Rapid loss of estrogenicity of steroid estrogens by UVA photolysis and photocatalysis over an immobilised titanium dioxide catalyst Water Res., 38 (2004), pp. 3233-3240, 10.1016/j.watres.2004.04.021

Crittenden et al., 1986 J.C. Crittenden, J.K. Berrigan, D.W. Hand Design tests for a constant diffusivity J. Water Pollut. Control Fed., 58 (1986), pp. 312-319

Crittenden et al., 2012 J.C. Crittenden, R.R. Trussell, D.W. Hand, K.J. Howe, G. Tchobanoglous Water Treatment: Principles and Design (third ed.), John Wiley \& Sons, Hoboken, NJ (2012)

Daugherty, 2011 E. Daugherty Analysis of Photocatalysis for Precursor Removal and Formation Inhibition of Disinfection Byproducts MS. Thesis Arizona State University, Tempe, AZ (2011)

Datson et al., 2003 G.P. Datson, J.C. Cook, R.J. Kavlock Uncertainties for endocrine disrupters: our view on progress Toxicol. Sci., 74 (2003), pp. 245-252, 10.1093/toxsci/kfg015

Dotson et al., 2010 A.D. Dotson, V.O.S. Keen, D. Metz, K.G. Linden UV/H2O2 treatment of drinking water increases post-chlorination DBP formation Water Res., 44 (2010), pp. 3703-

3713, 10.1016/j.watres.2010.04.006

Gerrity et al., 2009 D. Gerrity, B. Mayer, H. Ryu, J. Crittenden, M. Abbaszadegan A comparison of pilot-scale photocatalysis and enhanced coagulation for disinfection byproduct mitigation Water Res., 43 (2009), pp. 1597-1610, 10.1016/j.watres.2009.01.010

Gerrity et al., 2008 D. Gerrity, H. Ryu, J. Crittenden, M. Abbaszadegan Photocatalytic inactivation of viruses using titanium dioxide nanoparticles and low-pressure UV light J. Environ. Sci. Heal. Part A Toxic Hazard. Subst. Environ. Eng., 43 (2008), pp. 1261-1270

Gerrity et al., 2010 D. Gerrity, B.D. Stanford, R.A. Trenholm, S.A. Snyder An evaluation of a pilot-scale nonthermal plasma advanced oxidation process for trace organic compound degradation Water Res., 44 (2010), pp. 493-504, 10.1016/i.watres.2009.09.029

Glauner et al., 2005 T. Glauner, F. Kunz, C. Zwiener, F. Frimmel Elimination of swimming pool water disinfection by-products with advanced oxidation processes Acta Hydrochim. Hydrobiol., 33 (2005), pp. 585-594

Hamidin et al., 2008 N. Hamidin, Q.J. Yu, D.W. Connell Human health risk assessment of chlorinated disinfection by-products in drinking water using a probabilistic approach Water Res., 42 (2008), pp. 3263-3274, 10.1016/j. watres.2008.02.029

Hand et al., 1995 D. Hand, D. Perram, J.C. Crittenden Destruction of DBP precursors with catalytic oxidation J. Am. Water Works Assoc., 87 (1995), pp. 84-96

Hanselman et al., 2003 T.A. Hanselman, D.A. Graetz, A.C. Wilkie Manure-borne estrogens as potential environmental contaminants: a review Environ. Sci. Technol., 37 (2003), pp. 5471-

$5478,10.1021 /$ es034410

Huang et al., 2008 X. Huang, M. Leal, Q. Li Degradation of natural organic matter by TiO2 photocatalytic oxidation and its effect on fouling of low-pressure membranes Water Res., 42 (2008), pp. 11421150, 10.1016/i.watres.2007.08.030

Kaneco et al., 2004 S. Kaneco, M.A. Rahman, T. Suzuki, H. Katsumata, K. Ohta Optimization of solar photocatalytic degradation conditions of bisphenol $A$ in water using titanium dioxide J. Photochem. Photobiol. A Chem., 163 (2004), pp. 419-424, 10.1016/j.jphotochem.2004.01.012

Karanfil et al., 1999 T. Karanfil, M. Kitis, J.E. Kilduff, A. Wigton Role of granular activated carbon surface chemistry on the adsorption of organic compounds. 2. natural organic matter Environ. Sci. Technol., 33 (1999), pp. 3225-3233 
Kidd et al., 2007 K. Kidd, P. Blanchfield, K. Mills, V. Palace, R. Evans, J. Lazorchak, R. Flick Collapse of a fish population after exposure to a synthetic estrogen Proc. Natl. Acad. Sci. U. S. A, 104 (2007), pp. 88978901

Kilduff et al., 1996 J.E. Kilduff, T. Karanfil, W.J. Weber Competitive interactions among components of humic acids in granular activated carbon adsorption systems: effects of solution chemistry Environ. Sci. Technol., 30 (1996), pp. 1344-1351

Kleiser and Frimmel, 2000 G. Kleiser, F.H. Frimmel Removal of precursors for disinfection by-products (DBPs)-differences between ozone- and OH-radical-induced oxidation Sci. Total Environ., 256 (2000), pp. 1-9

Krasner et al., 2006

S.W. Krasner, H.S. Weinberg, S.D. Richardson, S.J. Pastor, R. Chinn, M.J. Sclimenti, G.D. Onstad, A.D. Thru ston Occurrence of a new generation of disinfection byproducts Environ. Sci. Technol., 40 (2006), pp. 7175-7185

Kuch and Ballschmiter, 2001 H.M. Kuch, K. Ballschmiter Determination of endocrine-disrupting phenolic compounds and estrogens in surface and drinking water by HRGC-(NCI)-MS in the picogram per liter range Environ. Sci. Technol., 35 (2001), pp. 3201-3206

Kulkarni and Chellam, 2010 P. Kulkarni, S. Chellam Disinfection by-product formation following chlorination of drinking water: artificial neural network models and changes in speciation with treatment Sci. Total Environ., 408 (2010), pp. 4202-4210, 10.1016/i.scitotenv.2010.05.040

Lamsal et al., 2011 R. Lamsal, M.E. Walsh, G.A. Gagnon Comparison of advanced oxidation processes for the removal of natural organic matter Water Res., 45 (2011), pp. 3263-3269, 10.1016/j.watres.2011.03.038

Li Puma et al., 2010 G. Li Puma, V. Puddu, H.K. Tsang, A. Gora, B. Toepfer Photocatalytic oxidation of multicomponent mixtures of estrogens (estrone (E1), 17 $\beta$-estradiol (E2), 17 $\alpha$-ethynylestradiol (EE2) and estriol (E3)) under UVA and UVC radiation: photon absorption, quantum yields and rate constants independent of photon absorp Appl. Catal. B Environ., 99 (2010), pp. 388-

397, 10.1016/i.apcatb.2010.05.015

Liu, 2009 H. Liu Hybrid Photocatalysis and Microfiltration Pretreatment for Organic Fouling Control of Reverse Osmosis Membrane National University of Singapore (2009)

Liu et al., 2007 S. Liu, M. Lim, K. Chiang, R. Amal, R. Fabris, C. Chow, M. Drikas A study on the removal of humic acid using advanced oxidation processes Separ. Sci. Technol., 42 (2007), pp. 1391$1404,10.1080 / 01496390701289799$

Liu et al., 2008a S. Liu, M. Lim, R. Fabris, C. Chow, K. Chiang, M. Drikas, R. Amal Removal of humic acid using TiO2 photocatalytic process--fractionation and molecular weight characterisation studies Chemosphere, 72 (2008), pp. 263-271, 10.1016/j.chemosphere.2008.01.061

Liu et al., 2008b S. Liu, M. Lim, R. Fabris, C. Chow, M. Drikas, R. Amal TiO2 photocatalysis of natural organic matter in surface water: impact on trihalomethane and haloacetic acid formation potential Environ. Sci. Technol., 42 (2008), pp. 6218-6223

Matsunaga et al., 1988 T. Matsunaga, R. Tomoda, T. Nakajima, N. Nakamura, T. Komine Continuous-sterilization system that uses photosemiconductor powders Appl. Environ. Microbiol., 54 (1988), pp. 1330-1333

Mayer et al., 2015 B.K. Mayer, E. Daugherty, M. Abbaszadegan Evaluation of the relationship between bulk organic precursors and disinfection byproduct formation for advanced oxidation processes Chemosphere, 121 (2015), pp. 39-46, 10.1016/i.chemosphere.2014.10.070

Mayer et al., 2014 B.K. Mayer, E. Daugherty, M. Abbaszadegan Disinfection byproduct formation resulting from settled, filtered, and finished water treated by titanium dioxide photocatalysis Chemosphere, 117 (2014), pp. 72-78

Mayer and Ryan, 2017 B.K. Mayer, D. Ryan Impact on disinfection byproducts using advanced oxidation processes for drinking water treatment A. Gil, L.A. Galeano, M.A. Vicente (Eds.), Applications of 
Advanced Oxidation Processes (AOPs) in Drinking Water Treatment. The Handbook of Environmental Chemistry, Springer, Berlin, Germany (2017), p. 42

Metz et al., 2011 D.H. Metz, M. Meyer, A. Dotson, E. Beerendonk, D.D. Dionysiou The effect of UV/H2O2 treatment on disinfection by-product formation potential under simulated distribution system conditions Water Res., 45 (2011), pp. 3969-3980, 10.1016/i.watres.2011.05.001

Nomiyama et al., 2007 K. Nomiyama, T. Tanizaki, T. Koga, K. Arizono, R. Shinohara Oxidative degradation of BPA using TiO2 in water, and transition of estrogenic activity in the degradation pathways Arch. Environ. Contam. Toxicol., 52 (2007), pp. 8-15, 10.1007/s00244-005-0204-7

Ohko et al., 2002 Y. Ohko, K.I. Iuchi, C. Niwa, T. Tatsuma, T. Nakashima, T. Iguchi, Y. Kubota, A. Fujishima 17ßestradiol degradation by TiO2 photocatalysis as a means of reducing estrogenic activity Environ. Sci. Technol., 36 (2002), pp. 4175-4181, 10.1021/es011500a

Orlov et al., 2007 A. Orlov, D.A. Jefferson, M. Tikhov, R.M. Lambert Enhancement of MTBE photocatalytic degradation by modification of TiO2 with gold nanoparticles Catal. Commun., 8 (2007), pp. 821 824, 10.1016/j.catcom.2006.08.040

Philippe et al., 2010a K.K. Philippe, C. Hans, J. MacAdam, B. Jefferson, J. Hart, S.A. Parsons Photocatalytic oxidation, GAC and biotreatment combinations: an alternative to the coagulation of hydrophilic rich waters? Environ. Technol., 31 (2010), pp. 1423-1434, 10.1080/09593330.2010.484074

Philippe et al., 2010b K.K. Philippe, C. Hans, J. MacAdam, B. Jefferson, J. Hart, S.A. Parsons Photocatalytic oxidation of natural organic matter surrogates and the impact on trihalomethane formation potential Chemosphere, 81 (2010), pp. 1509-1516, 10.1016/j.chemosphere.2010.08.035

Potter and Wimsatt, 2005 B.B. Potter, J.C. Wimsatt Method 415.3 - Measurement of Total Organic Carbon, Dissolved Organic Carbon and Specific UV Absorbance at $254 \mathrm{Nm}$ in Source Water and Drinking Water (2005) Washington, D.C

Richardson et al., 2007 S.D. Richardson, M.J. Plewa, E.D. Wagner, R. Schoeny, D.M. Demarini Occurrence, genotoxicity, and carcinogenicity of regulated and emerging disinfection by-products in drinking water: a review and roadmap for research Mutat. Res., 636 (2007), pp. 178-

242, 10.1016/i.mrrev.2007.09.001

Rodriguez-Mozaz et al., 2004 S. Rodriguez-Mozaz, M.J. López de Alda, D. Barceló Monitoring of estrogens, pesticides and bisphenol $A$ in natural waters and drinking water treatment plants by solid-phase extraction-liquid chromatography-mass spectrometry J. Chromatogr. A, 1045 (2004), pp. 85 -

92, 10.1016/j.chroma.2004.06.040

Rosenfeldt and Linden, 2004 E.J. Rosenfeldt, K.G. Linden Degradation of endocrine disrupting chemicals bisphenol A, ethinyl estradiol, and estradiol during UV photolysis and advanced oxidation processes Environ. Sci. Technol., 38 (2004), pp. 5476-5483, 10.1021/es035413p

Ryu et al., 2008 H. Ryu, D. Gerrity, J.C. Crittenden, M. Abbaszadegan Photocatalytic inactivation of Cryptosporidium parvum with TiO(2) and low-pressure ultraviolet irradiation Water Res., 42 (2008), pp. 1523-1530, 10.1016/i.watres.2007.10.037

Sarathy and Mohseni, 2010 S. Sarathy, M. Mohseni Effects of UV/H2O2 advanced oxidation on chemical characteristics and chlorine reactivity of surface water natural organic matter Water Res., 44 (2010), pp. 4087-4096, 10.1016/j. watres.2010.05.025

Sarkar et al., 2014 S. Sarkar, S. Ali, L. Rehmann, G. Nakhla, M.B. Ray Degradation of estrone in water and wastewater by various advanced oxidation processes J. Hazard Mater., 278 (2014), pp. 16-

24, 10.1016/i.jhazmat.2014.05.078

Schwarzenbach et al., 2005 R.P. Schwarzenbach, P.M. Gschwend, D.M. Imboden Environmental Organic Chemistry John Wiley (2005) 
Sornalingam et al., 2016 K. Sornalingam, A. McDonagh, J.L. Zhou Photodegradation of estrogenic endocrine disrupting steroidal hormones in aqueous systems: progress and future challenges Sci. Total Environ., 550 (2016), pp. 209-224, 10.1016/j.scitotenv.2016.01.086

Stevenson, 1994 F. Stevenson Humus Chemistry: Genesis, Composition, Reactions John Wiley \& Sons, New York City, NY (1994)

Thiruvenkatachari et al., 2007 R. Thiruvenkatachari, T.O. Kwon, J.C. Jun, S. Balaji, M. Matheswaran, I.S. Moon Application of several advanced oxidation processes for the destruction of terephthalic acid (TPA) J. Hazard Mater., 142 (2007), pp. 308-314, 10.1016/j.jhazmat.2006.08.023

Thurman, 1982 E.M. Thurman Molecular size of aquatic humic substances Org. Geochem., 4 (1982), pp. 27-35

Toor and Mohseni, 2007 R. Toor, M. Mohseni UV-H2O2 based AOP and its integration with biological activated carbon treatment for DBP reduction in drinking water Chemosphere, 66 (2007), pp. 20872095, 10.1016/i.chemosphere.2006.09.043

USEPA, 2006a USEPA National Primary Drinking Water Regulations: Stage 2 Disinfectants and Disinfection Byproducts Rule (2006)

USEPA, 2006b USEPA Ultraviolet Disinfection Guidance Manual for the Final Long Term 2 Enhanced Surface Water Treatment Rule (2006) Washington, D.C

Wert et al., 2009 E.C. Wert, F.L. Rosario-Ortiz, S.A. Snyder Using ultraviolet absorbance and color to assess pharmaceutical oxidation during ozonation of wastewater Environ. Sci. Technol., 43 (2009), pp. 48584863, 10.1021/es803524a

Westerhoff et al., 2005 P. Westerhoff, Y. Yoon, S. Snyder, E. Wert Fate of endocrine-disruptor, pharmaceutical, and personal care product chemicals during simulated drinking water treatment processes Environ. Sci. Technol., 39 (2005), pp. 6649-6663

Yamamoto et al., 2003 H. Yamamoto, H.M. Liljestrand, Y. Shimizu, M. Morita Effects of physical-chemical characteristics on the sorption of selected endocrine disruptors by dissolved organic matter surrogates Environ. Sci. Technol., 37 (2003), pp. 2646-2657

Yoon et al., 1998 S. Yoon, C. Lee, K. Kim, A. Fane Effects of calcium ion on the fouling of nanofilter by humic acid in drinking water production Water Res., 32 (1998), pp. 2180-2186

Yu et al., 2006 J.C. Yu, T.Y. Kwong, Q. Luo, Z. Cai Photocatalytic oxidation of triclosan Chemosphere, 65 (2006), pp. 390-399, 10.1016/i.chemosphere.2006.02.011

Zhang et al., 2007 Y. Zhang, J.L. Zhou, B. Ning Photodegradation of estrone and 17ß-estradiol in water Water Res., 41 (2007), pp. 19-26, 10.1016/j.watres.2006.09.020

Zhao et al., 2006 Z.-Y. Zhao, J.-D. Gu, X.-J. Fan, H.-B. Li Molecular size distribution of dissolved organic matter in water of the Pearl River and trihalomethane formation characteristics with chlorine and chlorine dioxide treatments J. Hazard Mater., 134 (2006), pp. 60-66, 10.1016/i.jhazmat.2005.10.032

Zularisam et al., 2006 A.W. Zularisam, A.F. Ismail, R. Salim Behaviours of natural organic matter in membrane filtration for surface water treatment - a review Desalination, 194 (2006), pp. 211231, 10.1016/i.desal.2005.10.030

\section{Appendix A. Supplementary data}

The following is the Supplementary data to this article: Download Word document (717KB)Help with docx files

Multimedia component 1. 